Article

\title{
Hydrometeorological Variability and Its Nonstationarity According to the Evolution Pattern of Indian Ocean Dipole over the East Asia Region
}

\author{
Jong-Suk Kim 1, Sun-Kwon Yoon ${ }^{2, *}$, and Sang-Myeong Oh ${ }^{3}$ \\ 1 State Key Laboratory of Water Re sources and Hydropower Enginee ring Science, W uhan Unive rsity, \\ Wuhan, 430072, P.R. China; jongsuk@whu.edu.cn (J.K.) \\ 2 De partment of Sa fety and Dis a ster Pre vention Re search, Seoul Institute of Technology, Seoul 03909, South \\ Korea;skyoon@sit.re.kr (S.Y.) \\ 3 OperationalSystems Development Department, National Institute of Meteorological Sciences, Jeju-do \\ 63568, South Korea; sicilia@korea.kr (S.O.) \\ * Correspondence: skyoon@sit.re.kr (S.Y.)
}

\begin{abstract}
In this study, we used statistical models to analyze nonlinear behavior links with atmospheric teleconnections between hydrometeorological variables and Indian Ocean Dipole (IOD) mode over the East Asia (EA) region. The analysis of atmospheric teleconnections was conducted using principal component analysis and singular spectrum analysis techniques. Moreover, the nonlinear lag-time correlations betw een climate indices and hydrological variables were calculated using mutual information (MI) techniques. The teleconnection-based nonlinear correlation coefficients (CCs) were higher than the linear CCs in each lag time. Additionally, we documented that the IOD has a direct influence on hydro-meteorological variables, such as precipitation within the Korean Peninsula (KP). Moreover, during the warm season (June to September) the variation of hydro-meteorological variables in the KP demonstrated significantly decreasing patterns during positive IOD years and they have neutral conditions during negative IOD years in comparison with long-term normal conditions. Finally, the revealed relationship betw een climate indices and hydro-meteorological variables and their possible changes will allow better understanding of stakeholder decision-making regarding to manage of freshwater management over the EA region. It can also provide useful data for long-range water resources prediction, to minimize hydrological uncertainties in a changing climate.
\end{abstract}

Keywords: hydrometeorological variability; Indian Ocean Dipole; principal component analysis; mutual information

\section{Introduction}

The frequency and intensity of extreme climate events have gradually increased due to the rising in global temperatures [1-3]. In addition, the seasonal variation of regional $w$ ater resource availability is also closely linked to characteristic changes in global climate [2,4-7]. These trends have significant implications for the efficient prediction and management of water resources. In other wor ds, it has become increasingly important to understand the relationship betw een extreme climatic events and the seasonal variability of hydro-meteorological variables.

Long-term hydro-meteorological changes are highly correlated with large-scale atmospheric teleconnections, which can predict the behavior of nonlinear climate systems in ocean-related climate indices, such as the El Niño/Southern Oscillation (ENSO) and the Indian Ocean Dipole (IOD) mode [8-11]. According to many studies on both ENSO and IOD, it is well-known that these systems are major sources of large scale, atmospheric environmental changes, and are closely correlated to seasonal variations, such as in precipitation and streamflow, within local patterns of hydrometeorological changes [10-14]. 
The IOD mode defined by Saji et al. [10] exhibits extreme rainfall and wet conditions in the East African region during positive IOD years. In contrast, during negative IOD years, wet conditions typically occur in the western part of the Indian Ocean and in Indonesia, which have a direct impact on dry conditions in East Africa. Several studies have argued that the IOD phenomenon currently runs ahead of ENSO events, as shown by the data on sea surface temperature(SST) rise, leading the latter by 3 to 6 months $[15,16]$. How ever, by conducting correlation analy ses between SST anomalies of ENSO and IOD in the tropical ocean region, various studies indicate that IOD is a phenomenon that occurs independently of ENSO, which is, in fact, an internal mode within the Indian Ocean region. The results of these studies also demonstrate that the Indian Ocean SST has been reported to show changing trends over time, impacting the cycle, intensity, and genesis [10,17-19].

The emerging issue of the IOD phenomenon has caused significant changes in the hydrometeorological patterns of several East Asian countries. However, quantitative studies on the characteristics of IOD phenomenon and its regional assessment are relatively insufficient for Korean watersheds. Therefore, in this study, we analyzed the influence of the long-term, hydrometeorological variability in the East Asian region by looking at the positive IOD (p-IOD) and the negative IOD (n-IOD) events, defined by Saji et al. [10]. We also analyzed the classification of IOD events in accordance with the patterns of both, positive and negative IOD events, as well as the evolution pattern of IOD, based on the results reported by Saji and Yamagata [19]. Our study had three specific objectives: (1) to analyze the significant large-scale pattern changes and long-term hydro-meteorological variability in the East Asia (EA) region, as well as in the KP region subwatershed, by the ocean-related, abnormal climate phenomenon, in accordance with the IOD mode index; (2) to investigate linkages between the atmospheric teleconnections and their possible mechanisms between hydro-meteorological variables and IOD indices over the KP using statistical methods; and (3) to perform a diagnostic study on the nonstationarity and the possibility of seasonal prediction for water resources management, using climate indices during significant IOD seasons over the KP and the EA region.

\section{Materials and Methods}

\subsection{Data}

To classify the Indian Ocean Dipole (IOD) events in the Tropical Indian Ocean (TIO), we used the SST data obtained from the National Centers for Environmental Prediction (NCEP) and the National Center for Atmospheric Research (NCAR) reanaly sis, version 2, and the 30-year climatology for the period of 1981-2010. In addition, we used the monthly Indian Ocean Dipole Mode Index (DMI) data obtained from the Japan Agency for Marine-earth Science and Technology (JAMSTEC), in Japan, and Hadley Centre Sea Ice and Sea Surface Temperature data set (HadISST). The Indian Ocean Dipole Mode Index (DMI) is defined as the sea surface temperature anomaly (SSTA) difference betw een the western $\left(50^{\circ} \mathrm{E}-70^{\circ} \mathrm{E}, 10^{\circ} \mathrm{S}-10^{\circ} \mathrm{N}\right)$ and southeastern $\left(90^{\circ} \mathrm{E}-110^{\circ} \mathrm{E}, 10^{\circ} \mathrm{S}\right.$-equator) regions of the $\mathrm{TIO}$ region [10]. Furthermore, we used the DMI calculated by APEC Climate Center (APCC), Busan, South Korea, which is used monthly SST from the National Oceanic and Atmospheric Administration (NOAA) Extended Reconstructed Sea Surface Temperature (ERSST) v4 in the TIO region. The time series data set is uploaded every month via APCC webpage.

The Global Precipitation Climatology Center (GPCC) monthly precipitation dataset, which consists in quality-controlled data from 67,200 stations worldwide, was used for the diagnosis on precipitation variability and its long-term changes over the East Asia region. The GPCC dataset has a regular grid with a spatial resolution of $0.5^{\circ} \times 0.5^{\circ}$ latitude by longitude from Deutscher Wetterdienst in Germany. The precipitation data for the 117 sub-w atersheds in the KP w ere obtained from the Water Resources Management Information System (WAMIS) of the Korean government. The average precipitation was calculated by the Thiessen polygon netw ork from the 125 precipitation gauge stations in Korea. The streamflow data the $117 \mathrm{sub}$-watersheds in the KP were calculated by using Precipitation-Runoff Modeling System (PRMS) model, which is widely applied for a long-term runoff simulation, developed by the US Geological Survey [20,21]. 


\subsection{Classification of IOD events}

To classify the Indian Ocean Dipole (IOD) events in the Tropical Indian Ocean (TIO), we used the SST data obtained from the National Centers for Environmental Prediction (NCEP) and the National Center for Atmospheric Research (NCAR) reanaly sis, version 2, and the 30 -year climatology for the period of 1981-2010. In addition, we used the monthly Indian Ocean Dipole Mode Index (DMI) data obtained from the Japan Agency for Marine-earth Science and Technology (JAMSTEC), in Japan, and Hadley Centre Sea Ice and Sea Surface Temperature data set (HadISST). The Indian Ocean Dipole Mode Index (DMI) is defined as the sea surface temperature anomaly (SSTA) difference between the western $\left(50^{\circ} \mathrm{E}-70^{\circ} \mathrm{E}, 10^{\circ} \mathrm{S}-10^{\circ} \mathrm{N}\right)$ and southeastern $\left(90^{\circ} \mathrm{E}-110^{\circ} \mathrm{E}, 10^{\circ} \mathrm{S}\right.$-equator) regions of the $\mathrm{TIO}$ region [10]. Furthermore, we used the DMI calculated by APEC Climate Center (APCC), Busan, South Korea, which is used monthly SST from the National Oceanic and Atmospheric Administration (NOAA) Extended Reconstructed Sea Surface Temperature (ERSST) v4 in the TIO region. The time series data set is uploaded every month via APCC webpage.

(a) DMI region in the Indian Ocean

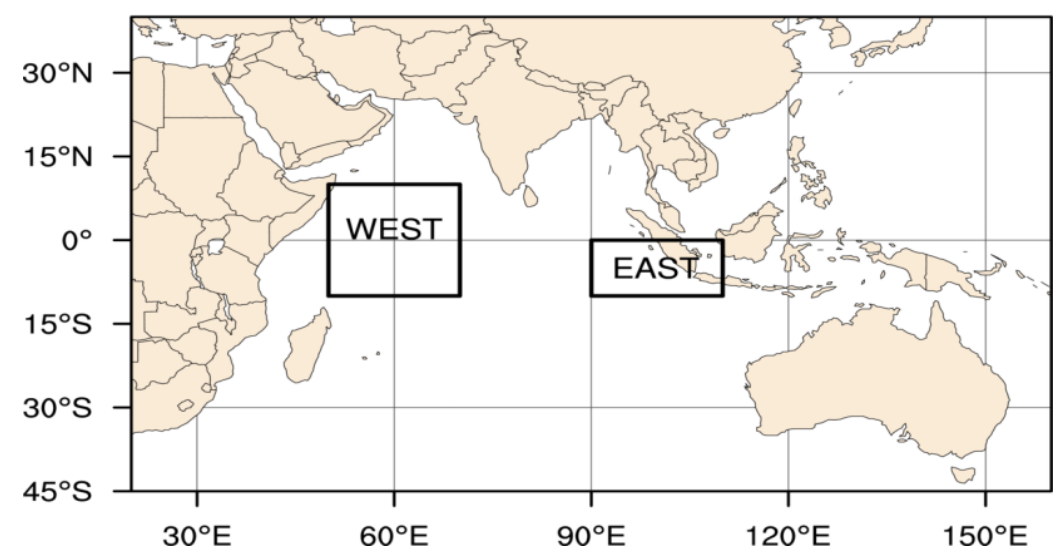

(b) Normalized anomaly time series of the DMI

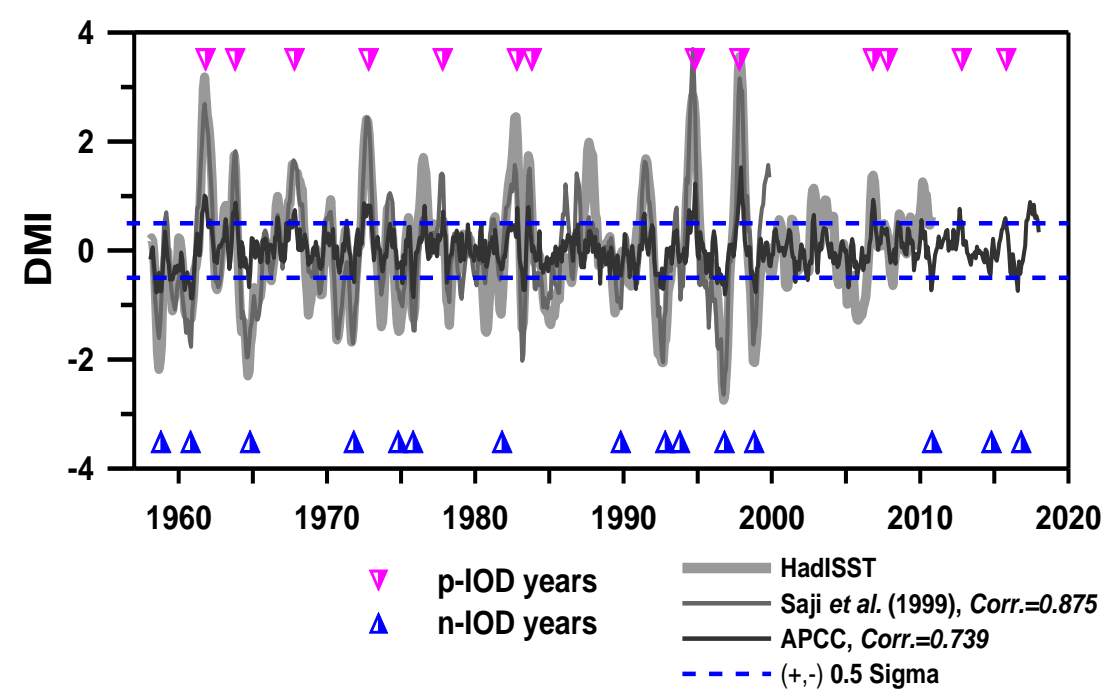

Figure 1. The dipole mode index (DMI) region in the Indian Ocean and normalized anomaly time series for DMI. (a) DMI region in the Indian Ocean; (b) normalized anomaly time series of the DMI. The light gray, darkgray, and solid black lines indica te calcula ted DMI indices by HadISST, Saji et al. [10] and APEC Climate Center (APCC), respectively.

In this study, we used the methodology proposed by Saji and Yamagata [19] to classify the positive and negative IOD events in the TIO region. The process includes the preprocessing of data and identifying criteria, which are as follows: 
Preprocessing of data: SST anomaly in the Western Indian Ocean (WIO, $10^{\circ} \mathrm{S}-10^{\circ} \mathrm{N}, 60^{\circ}$ $\left.80^{\circ} \mathrm{E}\right)$ and Eastern Indian Ocean (EIO, $\left.10^{\circ} \mathrm{S}-0^{\circ}, 90^{\circ}-110^{\circ} \mathrm{E}\right)$, and zonal wind anomaly over the equator $\left(\mathrm{U}_{\mathrm{e} q}\right.$, area-averaged wind anomaly over $\left.5^{\circ} \mathrm{S}-5^{\circ} \mathrm{N}, 70^{\circ}-90^{\circ} \mathrm{E}\right)$ were first detrended. A 3-month running mean was then applied once over the three-time series data to reduce theimpact of intra-seasonal fluctuations.

2) Identifying criteria:Dipole Mode Index (DMI) and $U_{\text {eq }}$ were required toexceed $0.5 \sigma$ in amplitude for at least 3 months. In addition, we required that theSSTA in WIO and EIO should be of opposite sign and the magnitude should exceed $0.5 \sigma$ for at least 3 months.

Figure 1 shows the DMI region in the Indian Ocean and normalized anomaly time series for the DMI between the Hadley Centre Sea Ice and Sea Surface Temperature data set (HadISST) by the NOAA Climate Prediction Center (CPC) and method proposed by Saji et al. [10]. Comparisons of two-time series data were calculated similarly, and we used longer period of the HadISST. Using the above procedure, we classified the thirteen strongest positive IOD years $(1961,1963,1967,1972,1977$, $1982,1983,1994,1997,2006,2007,2012$, and 2015), and the fifteen strongest negative IOD years (1958, $1960,1964,1971,1974,1975,1981,1989,1992,1993,1996,1998,2010,2014$, and 2016) based on the HadISST data from 1956 to 2018.

\subsection{Principal component analysis}

Singular spectrum analysis (SSA) is a non-parametric spectral estimation method that reduces dispersion by changing the coordinates in time series through techniques derived from principal component analysis (PCA), which enables the extraction of information from noisy time series. By removing the non-harmonic components from the original time series data, one can more easily understand its long-term frequency and trend [22]. SSA embeds the data of a time series $\mathrm{X}_{\mathrm{i}}(1<\mathrm{i}<\mathrm{N})$ in a vector space of dimension $\mathrm{M}$ and applies the method of the empirical orthogonal function (EOF) to it. This enables the projection of the original data in orthogonal functions EOF 1 and EOF 2. Thus, by composing the axis using these EOFs, the trend and cycle, and therefore the tendency of the total variance in the data, are more clearly apparent.

To separate the non-harmonic components, the size of the eigenvalues is defined by the orthogonal process. The orthogonal function is calculated between $\alpha_{i}^{1}$ and $\alpha_{i}^{2}$, the orthogonal coefficients of the principle component (PC1) and PC2 time series, to correspond with the harmonic components in the original coordinates $\mathrm{X}$ and $\mathrm{Y}$. Finally, it is converted to the reconstruction component (RC) to $\mathrm{R}_{\mathrm{i}}^{1}$ and $\mathrm{R}_{\mathrm{i}}^{2}$. It is possible to configure the estimation forecasting model to reflect specific characteristics (such as frequency and trend) in the original data. By using Eq. (1) to reconstruct the data, it is possible to replace the original data with a new time series, which has constant frequency and less noise.

$$
\begin{array}{ll}
\left(\mathrm{R}_{\mathrm{A}} \mathrm{X}\right)_{\mathrm{i}}=\frac{1}{\mathrm{i}} \sum_{\mathrm{j}=1}^{\mathrm{i}} \sum_{\mathrm{k} \in \mathrm{A}}^{\mathrm{i}} \alpha_{\mathrm{i}-\mathrm{j}}^{\mathrm{k}} \mathrm{E}_{\mathrm{j}}^{\mathrm{k}} & , 1 \leq \mathrm{i} \leq \mathrm{M}-1 \\
\left(\mathrm{R}_{\mathrm{A}} \mathrm{X}\right)_{\mathrm{i}}=\frac{1}{\mathrm{M}} \sum_{\mathrm{j}=1}^{\mathrm{M}} \sum_{\mathrm{k} \in \mathrm{A}}^{\mathrm{i}} \alpha_{\mathrm{i}-\mathrm{j}}^{\mathrm{k}} \mathrm{E}_{\mathrm{j}}^{\mathrm{k}} & , \mathrm{M} \leq \mathrm{i} \leq \mathrm{N}-\mathrm{M}+1 \\
\left(\mathrm{R}_{\mathrm{A}} \mathrm{X}\right)_{\mathrm{i}}=\frac{1}{\mathrm{~N}-\mathrm{i}+1} \sum_{\mathrm{j}=1-\mathrm{N}+\mathrm{M}}^{\mathrm{i}} \sum_{\mathrm{k} \in \mathrm{A}}^{\mathrm{i}} \alpha_{\mathrm{i}-\mathrm{j}}^{\mathrm{k}} \mathrm{E}_{\mathrm{j}}^{\mathrm{k}} & , \mathrm{N}-\mathrm{M}+2 \leq \mathrm{i} \leq \mathrm{N}
\end{array}
$$

where $\alpha_{i}^{k}$ is an orthogonal coefficient, $E_{j}^{k}$ is the empirical orthogonal function $(1 \leq k \leq M), M$ indicates a dimension, and $\tau$ is the sampling rate.

\subsection{Mutual information}

Mutual information (MI) is one of the most popular measures of how much one random variable (Y) tells us about another random variable (X); it can also be thought of as the reduction in uncertainty about one random variable given some knowledge of another variable. This is a useful tool for the calculation of a nonlinear correlation between different data sets. Here, we used MI to extract 
information about the nonlinear correlation betw een climate indices and hydrological variables in the KP.

If we have two kinds of time series data sets, such as $\left(s_{1}, s_{2}, s_{3}, \cdots, s_{n}, q_{1}, q_{2}, q_{3}, \cdots, q_{n}\right)$; where $n$ is the observed periods, then the MI value between observation $s_{i}$ and $q_{j}$ is defined by Moon et al. [23] as follow s by Eq. (2):

$$
M I_{s, q}\left(s_{i}, \boldsymbol{q}_{j}\right)=\log _{2}\left(\frac{P_{s, q}\left(s_{i}, q_{j}\right)}{P_{s}\left(s_{i}\right) P_{q}\left(q_{j}\right)}\right)
$$

where $\boldsymbol{P}_{\boldsymbol{s}, \boldsymbol{q}}\left(\boldsymbol{s}_{\boldsymbol{i}}, \boldsymbol{q}_{\boldsymbol{j}}\right)$ indicates thejoint probability density function between $\boldsymbol{s}$ and $\boldsymbol{q}$, calculated by a time series of $\left(\boldsymbol{s}_{\boldsymbol{i}}, \boldsymbol{q}_{j}\right) ; \boldsymbol{P}_{\boldsymbol{s}}\left(\boldsymbol{s}_{\boldsymbol{i}}\right)$ and $\boldsymbol{P}_{\boldsymbol{q}}\left(\boldsymbol{q}_{\boldsymbol{j}}\right)$ are the marginal probability densities calculated from $\boldsymbol{s}_{\boldsymbol{i}}$ and $\boldsymbol{q}_{\boldsymbol{j}}$, respectively. The overall concern is the correlation between the two series of data. The average mutual information $\left(\boldsymbol{I}_{\boldsymbol{s}, \boldsymbol{q}}\right)$ of two discrete random variables $\boldsymbol{s}$ and $\boldsymbol{q}$ can be defined by Eq. (3):

$$
I_{s, q}=\sum_{i, j} P_{s, q}\left(s_{i}, q_{j}\right) \log _{2}\left(\frac{P_{s, q}\left(s_{i}, q_{j}\right)}{P_{S}\left(s_{\mathrm{i}}\right) P_{q}\left(q_{j}\right)}\right)
$$

where $P_{s, q}\left(s_{i}, q_{j}\right)$ is the joint probability distribution function of $\mathrm{X}$ and $\mathrm{Y}$, and $P_{s}\left(s_{i}\right)$ and $P_{q}\left(q_{j}\right)$ are the marginal probability distribution functions of $s$ and $q$, respectively. This equation is useful to search for the components in multivariate sampling whether independent and dependent. In particular, Martinerie et al. [24] and Gao and Zheng [25] used MI techniques when constructing the state space for appropriatelag time selection in the orthogonal time series.

MI analysis between climate indices and hydro-meteorological variables was performed using Eq. (4), proposed by Joe [26], following the standard normal distribution of the axis (X, Y) and its linear correlation analysis.

$$
I(X ; Y)=-0.5 \log \left[1-\rho(X, Y)^{2}\right]
$$

where $I(X ; Y)$ indicates the calculated average MI value through MI analysis and $\rho(X, Y)$ is the linear correlation between $X$ and $Y$.

MI based on the nonlinear correlation coefficient can be used to obtain $\lambda[0 \leq \lambda \leq 1]$. To calculate $\lambda$ by estimation of average MI value (following the standard normal distribution in the two variables $X$ and $Y$ ), the following Eq. (5), proposed by Joe [26] and Granger and Lin [27], w as used:

$$
\hat{\lambda}(X, Y)=\sqrt{1-\exp [-2 \hat{I}(X, Y)]}
$$

where $\hat{l}(X, Y)$ is the average $M I$ value from the two variables $X$ and $Y$ and $\hat{\lambda}(X, Y)$ is a nonlinear correlation coefficient estimated from average MI value betw een the two variables $(X, Y)$.

In this study, we used a linear regression (LR) method using Eq. (4) with the estimated average MI values and a nonlinear regression using Eq. (5) with 2-D Kernel Density Estimators (KDE) proposed by Moon et al. [23]. The $90 \%$ confidence limits were estimated using 1,000 bootstrap resampling replications, allowing for a more accurate calculation of the confidence limits, given the limited data.

\section{Results}

3.1 Large-scale ocean environment of the TIO 
Based on the positive and negative IOD years defined above, a composite analysis of summer (June-September) SSTA in the Tropical Indian Ocean was conducted (Figure 2). According to the results, the summer SSTA condition analyzed in this study was not significantly different from the autumn pattern defining the IOD [10,17-19]. During the positive IOD years, cold SST anomaly patterns appeared in the East Indian Ocean, including Indonesia and the maritime continent, and warm SSTA patterns emerged in the Indian Ocean in the equatorial region. The warm and cold SST distributions were not extensive, but strong signals were observed in the East Indian Ocean. On the other hand, although not strongly dependent on the IOD phases, there was a warm and cold SSTA distribution over wide areas in the West Indian Ocean. Furthermore, in most areas where w arm and cold signals appeared, the confidence level was greater than $95 \%$.

Many recent studies show that these different SST anomaly patterns in the TIO region may affect air circulation changes. Moreover, they have detected several teleconnection-based significant changes in different regions on seasonal precipitation over the countries in Northeast Asia. The physical mechanism of the developing and decaying phases of the IOD mode in the atmosphere on a large scale have not yet been clearly revealed, although there are a number of reliable studies; some of them diagnostic, others on the regional impacts of the p-IOD and n-IOD [10,17-19].

\section{a. $\mathrm{p}-I O D$ years}

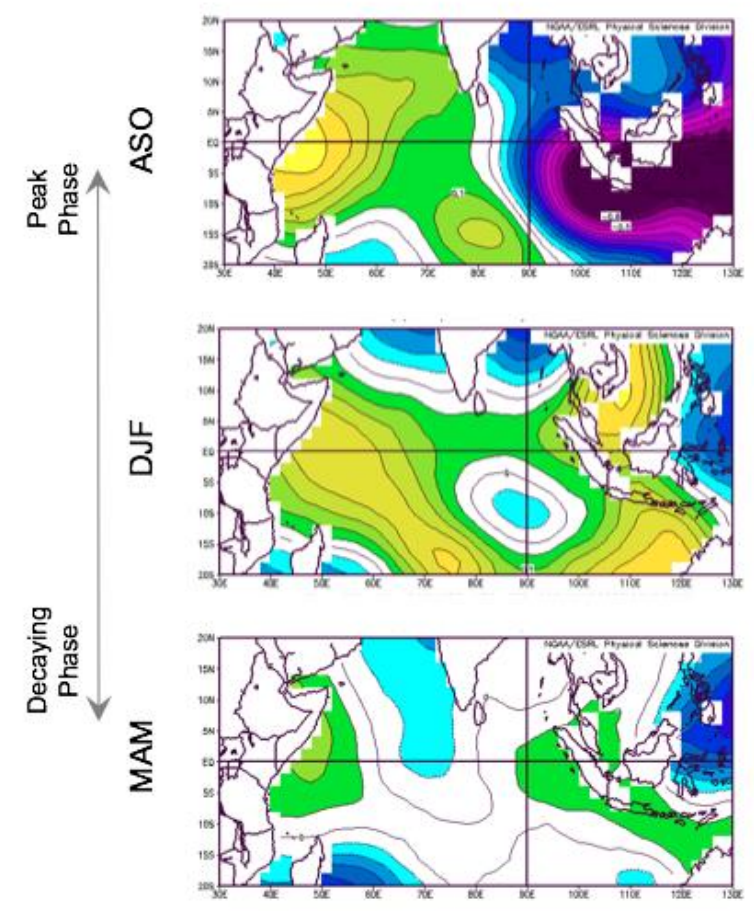

\section{b. $n-I O D$ years}

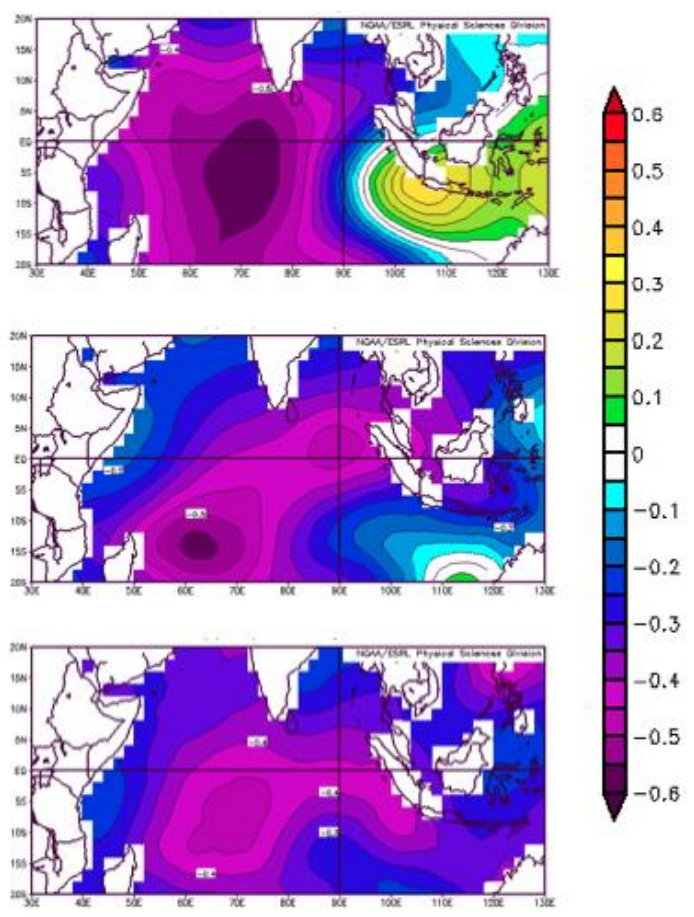

Figure 2. Composite sea surface temperature anomalies of mean SST in the TIOregion during positive and negative IOD years, during the period from August to May in the following year. NOAA Extended SST V4 (ERSST) monthly da ta we re used for the SSTA composite a nalysis; climatology data were used for the normal years from 1981 to 2010.

\subsection{Precipitation and low-level wind over East Asia}

Figure 3 shows the composite anomalies (1981-2010 climatology) of the Global Precipitation Climatology Center (GPCC) precipitation and $850 \mathrm{hPa}$ wind over Northeast Asia during strong IOD events, in the same way as SSTA. We extracted monthly precipitation for 1901-2016 from the GPCC reanalysis version 6.0 at $0.5^{\circ} \times 0.5^{\circ}$ spatial resolution, and for the wind the NCEP/NCAR reanalysis 1 data was used. During the positive IOD years, there were more precipitation signals than usual in the southern part of China, including the South China Sea, and southern part of Japan, with cyclonic circulation patterns. Meanwhile, there w as a high-pressure anti-cyclonic pattern over eastern China 
and the KP (Figure 3a). In the negative IOD years, there was a drier signal than normal in the South China Sea and southern China, along with a high-pressure anti-cyclonic pattern (Figure 3b). On the other hand, inland and eastern regions of China and Japan showed wetter signals than usual with a cyclonic circulation pattern. How ever, the KP w as located betw een the tw o cyclonic circulations, and the district precipitation signal was not visible. How ever, the signal was less dry than that in the positive IOD years. Precipitation had a topographic effect and local variability in addition to large circulation, which did not show as high a confidence level as the SSTA variation.

(a) $\mathrm{p}-$ IOD

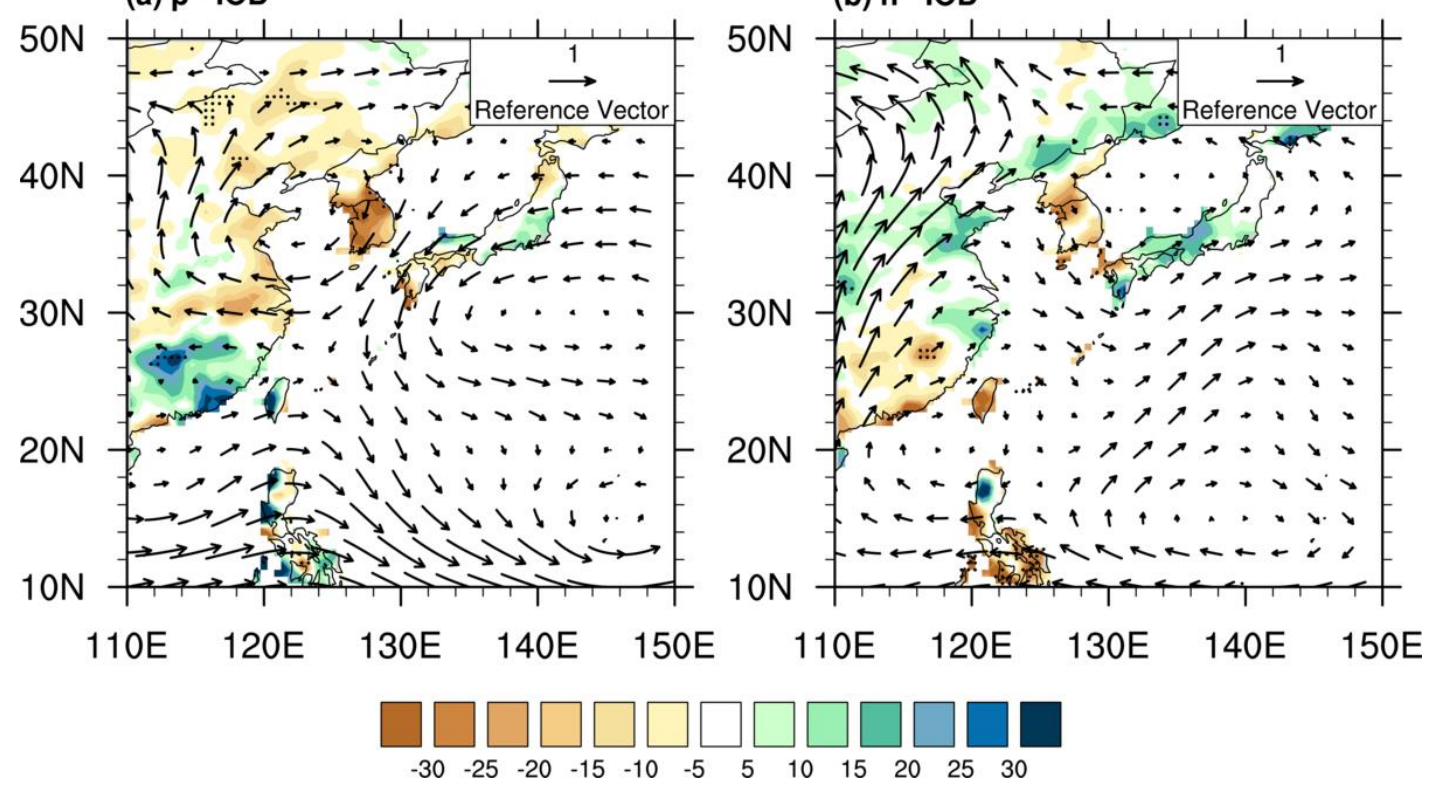

Figure 3. Composite anomalies (1981-2010 climatology) of the GPCC precipitation from June to Septe mber during IOD events over the Northe ast Asia region.

\subsection{Nonlinear atmospheric teleconnections over the KP}

The IOD phenomenon in the TIO region induced large-scale environmental atmospheric climate pattern changes. To understand their local hydro-environmental impacts in the KP, it is necessary to analyze the linear and nonlinear correlations and their lag time correlations betw een climat eindices and hydro-meteorological variables. In general, abnormal SST in the TIO region has triggering effects for the troposphere temperature rise. The atmospheric teleconnection links with the jet stream can affect its local hydro-meteorological variations w orldwide, even in the countries in the East Asia (EA) region.

To explore these teleconnections betw een climate indices and hydro-meteorological variables in the KP region, wetransformed the normalized time series data for stationary processes. Additionally, the low frequency data in the time series data sets were extracted by PCA using a SSA technique. Furthermore, thejoint probability distribution density function w as derived using the Kernel Density Estimation (KDE). In general, the nonlinear correlation is high or low, as the sum of the MI values quantitatively represents the correlation. The MI method has a conditional occurrence probability by section. If the MI value is large, the nonlinear correlation between the two data sets is also large. Where appropriatelag times are selected, the MI technique can be used to estimate the probability density function using a Kernel function in a non-parametric manner. 


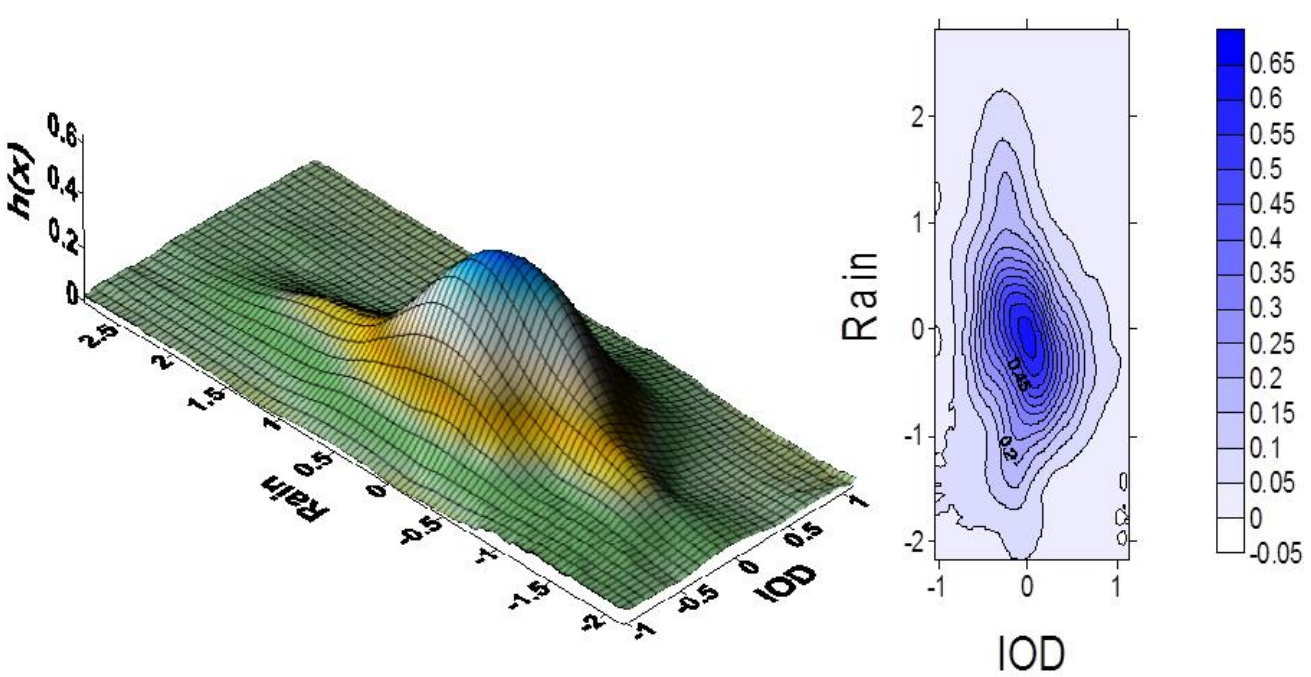

Figure 4. Lag-1 month nonline ar correlation of joint probability kernel density estimations (J-KDEs) between normalized 5-month moving a verage precipita tion and IOD index in the Kore an Peninsula.

Figure 4 shows the joint probability kernel density functions among normalized 5-month moving average precipitation and the $\mathrm{p}$-/n-IOD indices, over the KP. The nonlinear lag time correlations are calculated by the mutual information (MI) and their lag-time correlations are simulated from lag-0 to lag-11. A result of the 3-D joint probability kernel density function as shown in Figure 4 is based on the MI results for lag- 1 month nonlinear correlation. For the precipitation of the $\mathrm{KP}$, the values of the probable mode corresponding to the vertices of the joint probability density function were $0.632,0.603$, and 0.601 , respectively, at lag time 1,3 , and 6 . Further, the values of the probable mode by the lag time tended to decrease. Furthermore, by analyzing the location of the central points of the joint probability Kernel density functions with precipitation and IOD index, we find out that the positive correlation between hydro-meteorological variable and IOD pattern changes in each lag time over the KP using MI techniques.

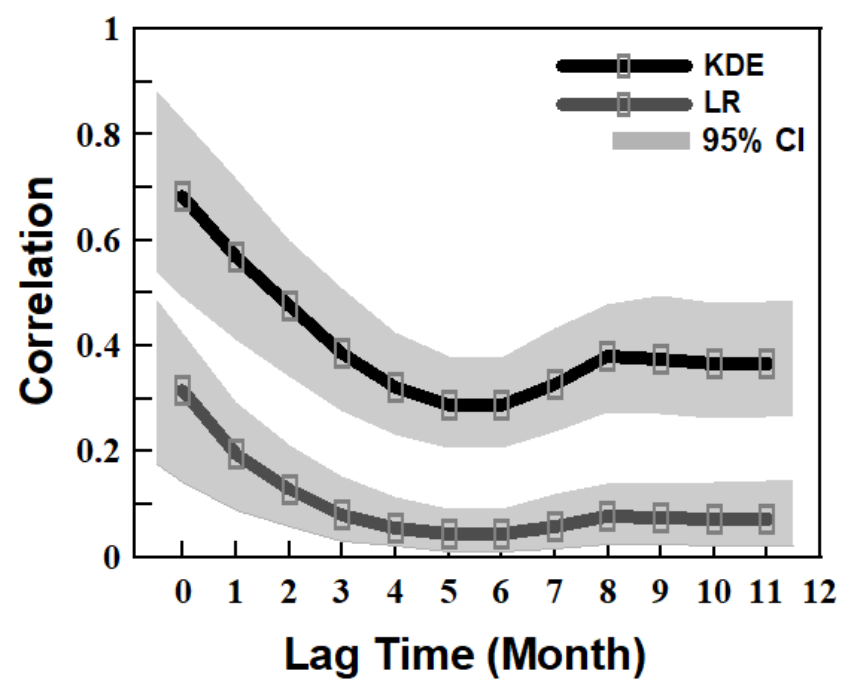

Figure 5. Nonlinear and linear lag-time CCs with 95\% confidence limits between IOD index and monthly precipitation over the KP and the EA region. Confidence limits are given by $5 \%$ and $95 \%$ quantiles of 1,000 bootstrap resampling.

Figure 5 shows the linear and the nonlinear correlation coefficients (CCs) with their 95\% confidence limits between climate indices and precipitation over the KP using KDE and LR approaches. As described in the methodology, we obtained the nonlinear behaviors and their quantitative correlation values from the equation proposed by Joe (1989), based on MI results. As 
shown in Figures 5, the lag-0 correlation was calculated as the highest correlation for both LR and KDE, which show s correlated with IOD index and KP rainfall (LR: 0.315, KDE: 0.684), although they had no lag time correlation. These time-lags indicate the existence on a nonlinear correlation between climate indices and hydrological variables, which shows that there is a possibility for a diagnostic study on seasonal prediction of $w$ ater resources over the KP and the EA region using ocean-related large-scale climate indices.

\subsection{Evolution pattern of the Indian Ocean Dipole and its local impacts}

We diagnosed the effects of hydro-meteorological variability over the KP and the East Asia Region due to the IOD pattern changes. Even if they are geographically remoted area, they can affect and hydrologically correlated by atmospheric-dynamic processes and their possible mechanism $[10,19]$. The positive and negative IOD events were analyzed from April, when the development began, to September, when it peaked, and until November, when it started to disappear. We investigated the effect of the IOD evolution pattern on the KP with a three-month time window, considering a one-month delay. The hatched polygons indicate statistically significant changes in annual and w arm seasons based on the $10 \%$ significance level by Student'st-test. It also shows a similar pattern to figures for characteristics of spatial variability change in the KP region caused by positive IOD and negative IOD events. Greater understanding of the hydrological patterns w as attained by a detailed examination at the sub-watershed scale. Looking at the detailed variations in the 117 subw atershed areas in the KP, we can capture their spatial and seasonal variability caused by IOD.

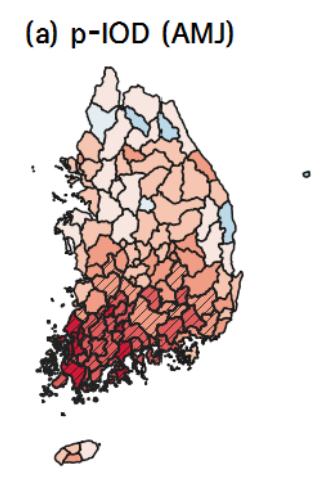

(d) $p-I O D(J A S)$

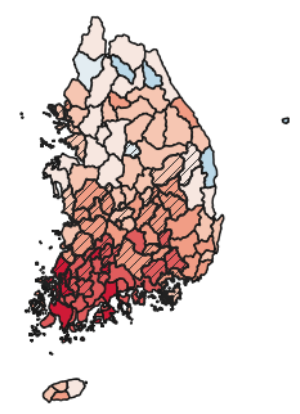

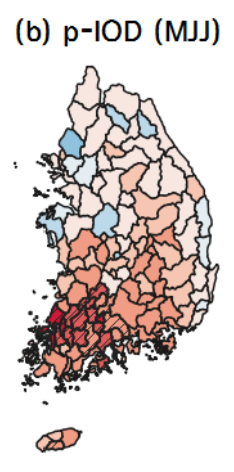

(e) $\mathrm{p}-$ IOD (ASO)

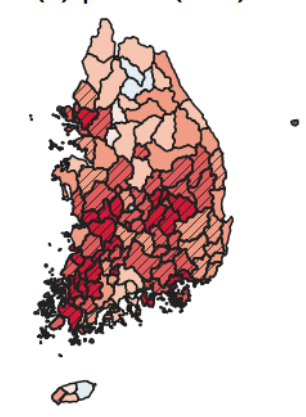

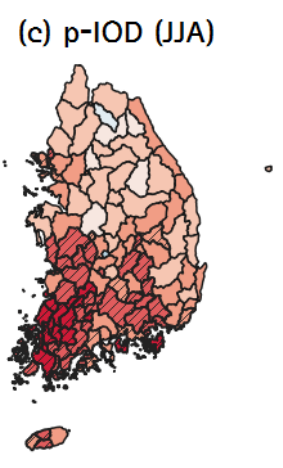

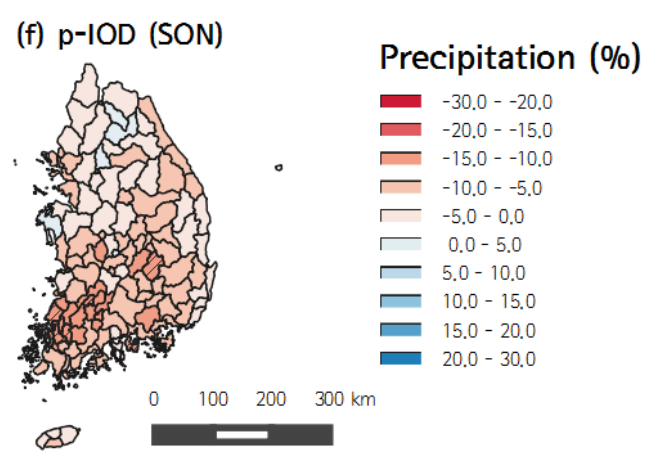

Figure 6. Evolution pattern of the seasonal rainfall in the KP in the context of the Indian Ocean Dipole mode during positive IOD years. Hatched polygons indica te statistically significant changes of season precipitation at $10 \%$ significance level. 


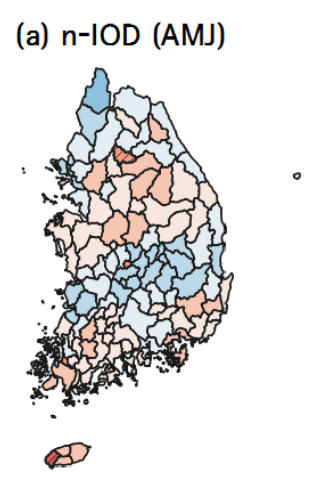

(d) $n-I O D(J A S)$

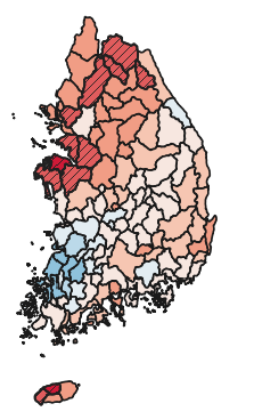

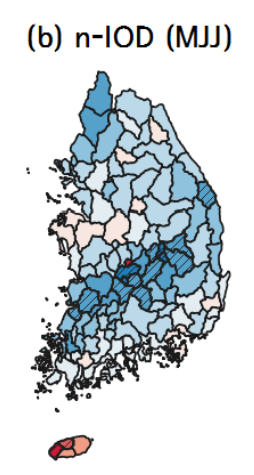

(e) $n-I O D(A S O)$

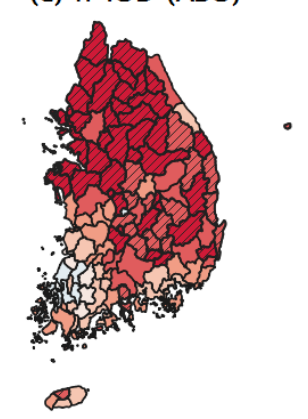

(c) n-IOD (JJA)

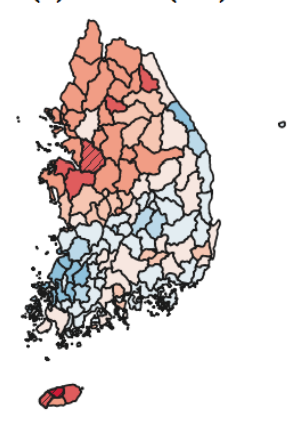

(f) $n-I O D(S O N)$

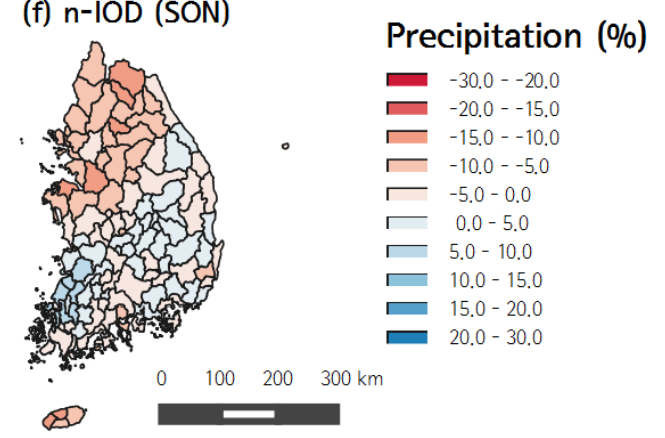

Figure 7. Evolution pattern of the seasonal rainfall in the KP in the context of the Indian Ocean Dipole mode during negative IOD years. Hatched polygons indicate statistically significant changes of season precipitation at $10 \%$ significance level.

Figure 6 shows the result of analysis of the change in precipitation in the KP according to the evolution pattern of the positive IOD years from April to November. Total precipitation in the KP decreased significantly from the long-term average: - $11.90 \%$ in AMJ (April-June), $-8.63 \%$ in MJJ (MayJuly), $-14.32 \%$ in JJA (June-August), $-9.92 \%$ in JAS (July-September), $-15.23 \%$ in ASO (AugustOctober), and $-7.14 \%$ in SON (September-November). Also, the total amount of precipitation change was analyzed using the t-test, and it was found that there was a significant decrease pattern in the southern part of the KP at $90 \%$ confidence level. In the case of the positive IOD phases, it was concluded that the pattern of decrease in precipitation was more likely to occur at a significant level in the southern part than in the middle northern part of the KP. Changes in this pattern persisted remarkably between April and November in the positive IOD years. In the ASO period (autumn season in Korea), a distinct pattern of decrease in precipitation occurred mainly in the central and southern regions of the KP.

Figure 7 shows the result of analysis of the change in precipitation in the KP according to the evolution pattern of the negative IOD years from April to November. Total precipitation in the KP tended to decrease or increase more than usual; - $0.71 \%$ in AMJ (April-June), +7.91\% in MJJ (MayJuly), $-1.39 \%$ in JJA (June-August), -4.05\% in JAS (July-September), -15.63\% in ASO (August-October), and $-1.07 \%$ in SON (September-November). We observed a pattern of a significant decrease of precipitation in the central part of the KP, although a pattern of increase in precipitation occurred in the southern part of the KP during the MJJ (May-July) period. In the case of the negative IOD phases, contrary to the positive IOD phases, it is concluded that the pattern of significant decrease in precipitation is more likely to appear in the northern part than in the cen tral and southern parts of the KP. These changes appear to be conspicuous between April and November, when the negative IOD is observed. In the ASO (August-October) period, a distinct pattern of precipitation reduction occurred in the central and northern regions of the KP.

\subsection{Long-term changes in seasonal precipitation}


Figure 8 shows the change in the 30-year-mean rainfall in the five major rivers of the Korean Peninsula. Figure 8a shows seasonal rainfall from August to October when the IOD is at its peak. Rainfall changes in Case 1 and Case 3 in all five rivers show a similar trend, and for Case 2, excluding rainfall in the IOD years, there w as an $11 \%$ to $27 \%$ increase in rainfall. This change in rainfall occurred in the Han River basin and was relatively abundant in the southern part of the Korean Peninsula. In the Youngsan River basin, it was analyzed that Case 1 and Case 3 showed a statistically significant increase in the 30-year-mean rainfall analysis while excluding rainfall in the positive IOD years, although there was an increase in seasonal rainfall, but no statistically significant change $(p>0.05)$.In the Han River basin, Case 1 and Case 2 showed statistically significant increases, whereas in case3 excluding the negative IOD years, there was an increase in seasonal rainfall, but no statistically significant change ( $p>0.1)$ w as analyzed. As show $n$ in the GPCC composite analy sis, the positive IOD years in the Youngsan river basin has less rainfall than long-term normal throughout the Korean Peninsula, especially in the central part of the Korean Peninsula, with the effects of rainfall reduction in the Han River basin. Figure 8b show s the change in the 30-year-mean rainfall in the five major river basins of the Korean Peninsula in March-May when the IOD crosses the peak and enters a period of decline. The IOD showed a statistically significant decline in the entire basin of the five rivers in contrast to the rainfall during the peak IOD season. The decline in seasonal rainfall (MAM) was noticeable in the Youngsan River basin and Seomjin river basin in the southern coastal region, Korea. During the positive IOD years, it was found that the entire Korean Peninsula was 2.6 percent to 9.4 percent larger than the average rainfall. In the case of the negative IOD years, less rainfall than usual occurred in the Geum River and other the other three basins, except for the Nakdong River Basin (3. 9\%). In the Han River basin, 7.4 percent less rainfall than in the average, followed by the Seomjin River basin (5.2 percent reduction in MAM rainfall) and Youngsan River basin (3.4 percent reduction in MAM rainfall). The summary result for each basin for seasonal precipitation is given in Table 1.

Table 1. Change s in sea sonal precipita tion from the long-term normal(1966-2016)

(unit: \%)

\begin{tabular}{|c|c|c|c|c|c|c|}
\hline \multirow{2}{*}{ River Basin } & \multicolumn{2}{|c|}{ ASO } & \multicolumn{4}{c|}{ MAM } \\
\cline { 2 - 7 } & Case I & Case II & Case I & Case II & Case III & Case IV \\
\hline Han River & -11.0 & 0.8 & 6.5 & -7.4 & $7.0(20.5)$ & -1.5 \\
\hline Nakdong River & -26.8 & -2.0 & 2.6 & 2.3 & $13.6(20.4)$ & 8.9 \\
\hline Geum River & -24.6 & 4.3 & 4.0 & 3.9 & $11.8(22.0)$ & -1.5 \\
\hline Sumjin River & -26.0 & 5.2 & 3.1 & -5.2 & $18.8(25.1)$ & 7.4 \\
\hline Youngsan River & -25.9 & 6.0 & 9.4 & -3.4 & $13.3(20.6)$ & 8.7 \\
\hline
\end{tabular}

Case I: positive IOD years, Case II: ne gative IOD years, Case III: Case I coincided with CT/WP El Nino, Case IV: Case II coincided with La Nina. The numerical value in parentheses shows the results of Case I coincided with CT El Nino. 
(a) Sea sonal Precipitation Anomaly (ASO)
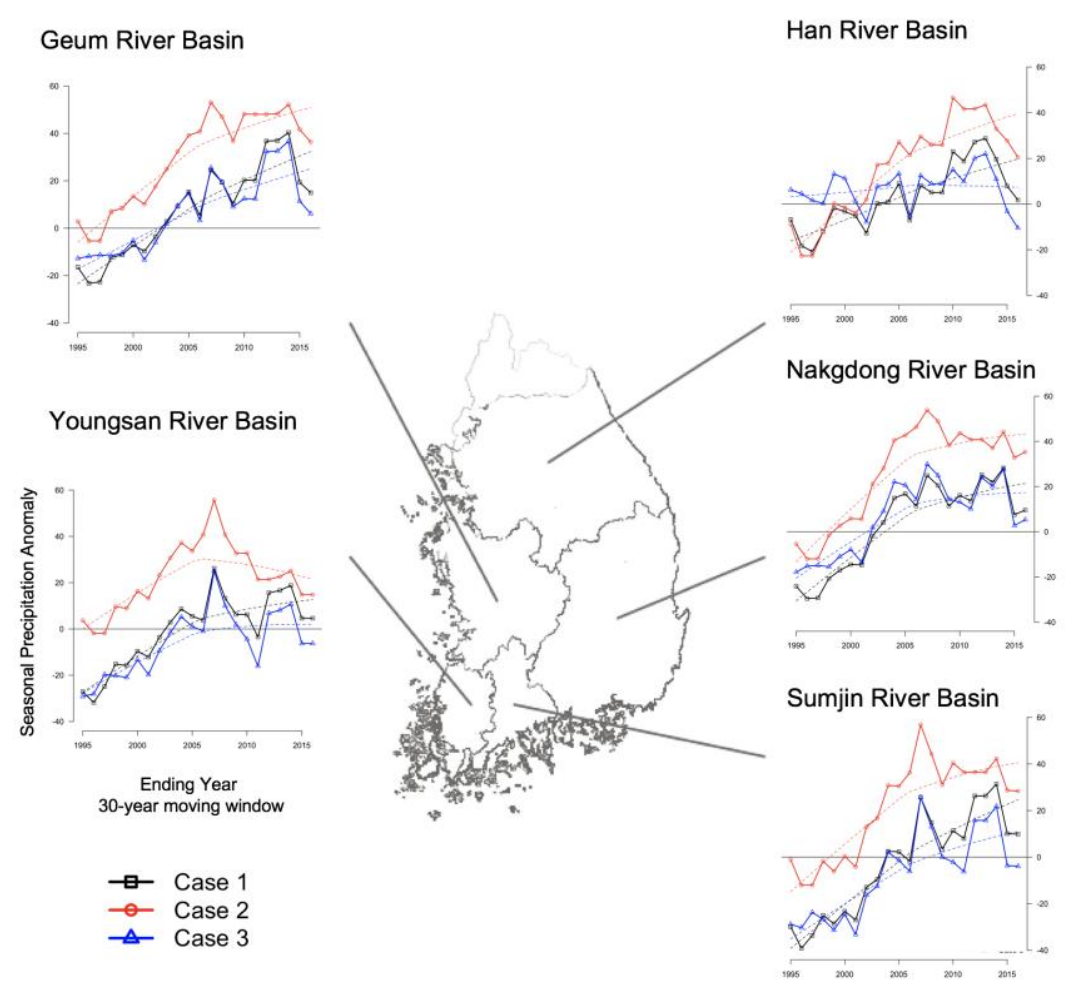

(b) Sea sonal Precipita tion Anomaly (MAM)
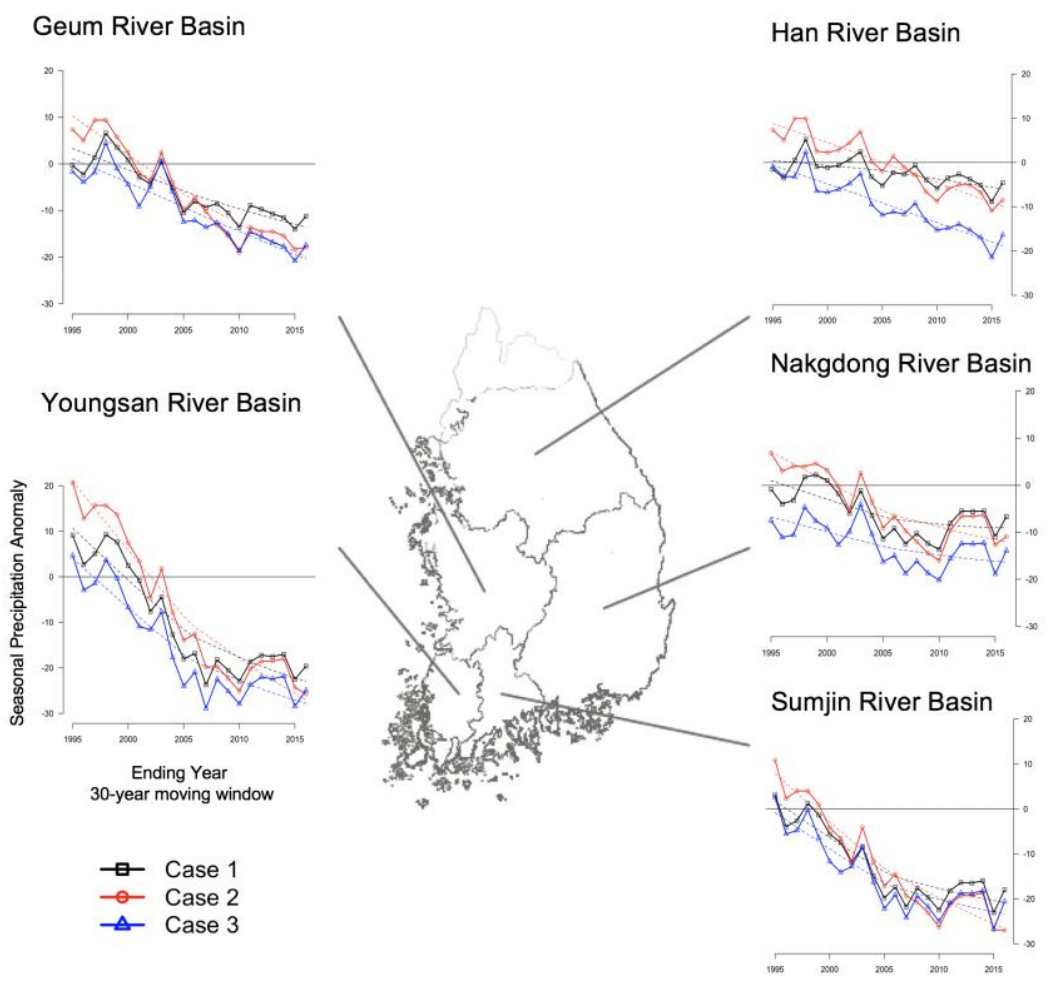

Figure 8. Changes in the 30-year-mean rainfall in the five major rivers of the Korean Peninsula. (a) Se a sonal Precipitation Anomaly (August-October). (b) Seasonal Precipita tion Anomaly (March-May). In each picture, Case1 shows the changes over time in the 30-year-mean rainfall without excluding the effects of IOD separately. Case 2 is the result of excluding the rainfall in the positive IOD years, and Case 3 shows the change in the 30-year-mean rainfall, excluding the rainfall in the nega tive IOD years. 


\subsection{Hydrometeorological variability and its local impacts}

During positive IOD events (Figure 9a, c), the annual/JJAS rainfall in the KP w as -7.14\%/-14.74\% lower than the long-term average annual/JJAS rainfall (1971-2000). The annual/JJAS streamflow during positive IOD events (Figure 9a, c) substantially decreased to $-11.61 \% /-16.69 \%$ in the basins of the KP. During negative IOD events (Figure 9b, d), the annual/JJAS rainfall in the KP slightly decreased to $-1.07 \% /-3.31 \%$. The composite analysis revealed that the annual/JJAS precipitation during positive IOD events were substantially lower than those during long-term normal years. In contrast, negative IOD events showed annual/JJAS precipitation slightly below normal conditions.

Figure 10 shows a scatter plot of percent change anomaly (departures from the 1971-2000 normal) changes between precipitation and streamflow in different season under abnormal climate conditions of IOD. The center of scatter plot of annual during IOD conditions shows positive IOD years $(-13.74 \%,-15.84 \%)$ and negative IOD years $(-4.30 \%,-3.95 \%)$, respectively. In spring (March to May, MAM) and autumn (September to November, SON), the characteristic changes of p-/n-IOD years are not clear, but there has increasing and decreasing tendency during spring and autumn, respectively (Fig. 10a, c). Especially, during summer (June to August, JJA) and winter (December to February, DJF), the characteristic changes of precipitation and streamflow can be clearly identified (Figure 10b, d). In summer, the amount of precipitation and streamflow show decreasing pattern during the p-IOD years. How ever, during winter, precipitation changes were clearly confirmed as decreased (increased) patterns during p-IOD (n-IOD) years, but the variation of streamflow was not large. Findings indicate that IOD events strongly influence the precipitation and streamflow and its sub-w atersheds in the KP. This show s a linkage of possible teleconnections and characteristic changes between tropical Indian ocean-related major climactic events and local hydrometeological variabilities over the KP.

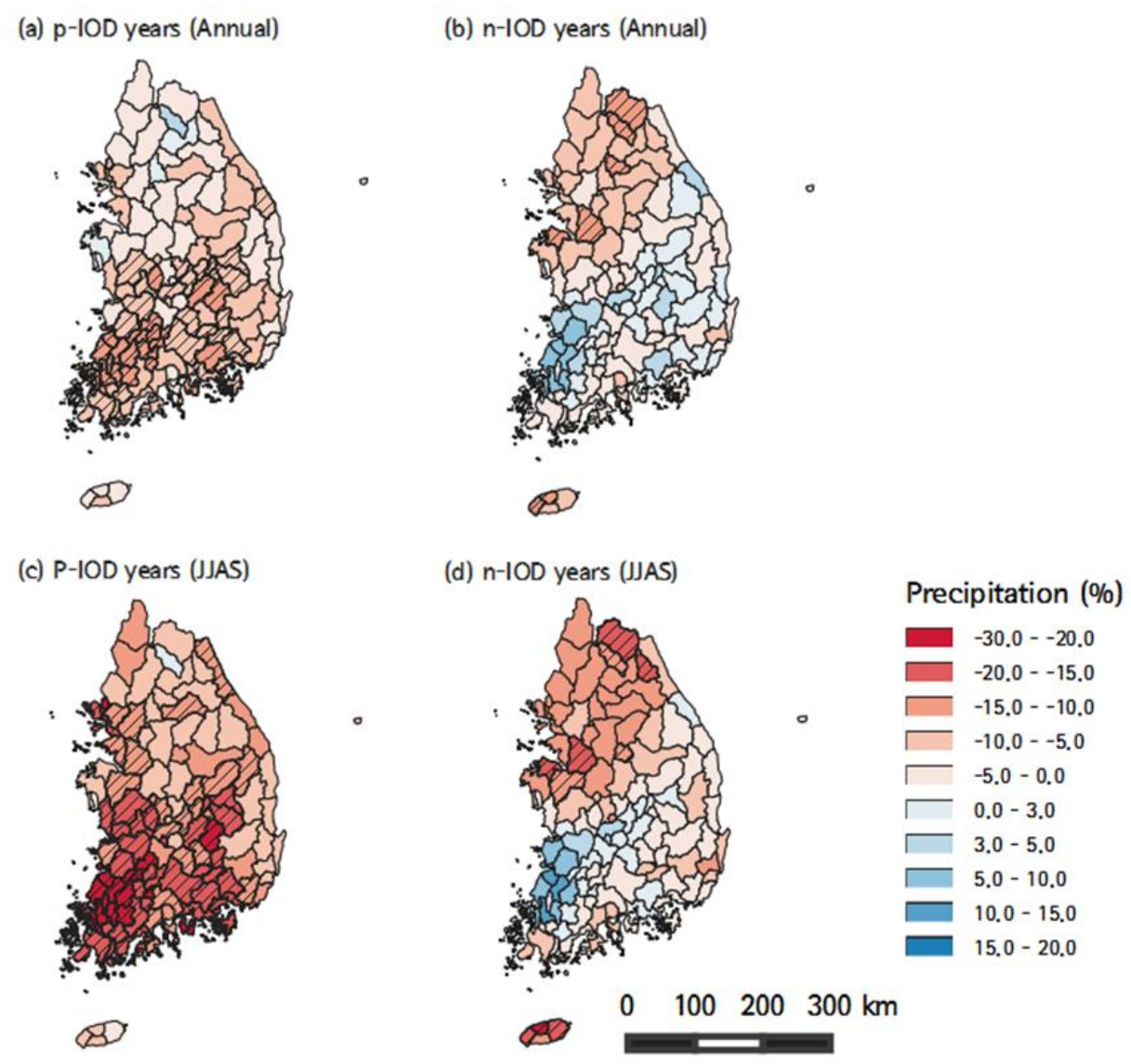

Figure 9. Composite anomalies of annual and JJAS rainfall during positive and negative IOD years. Hatched polygons indica te statistically significant changes in precipita tion at $10 \%$ significance le vel. 
(a) MAM

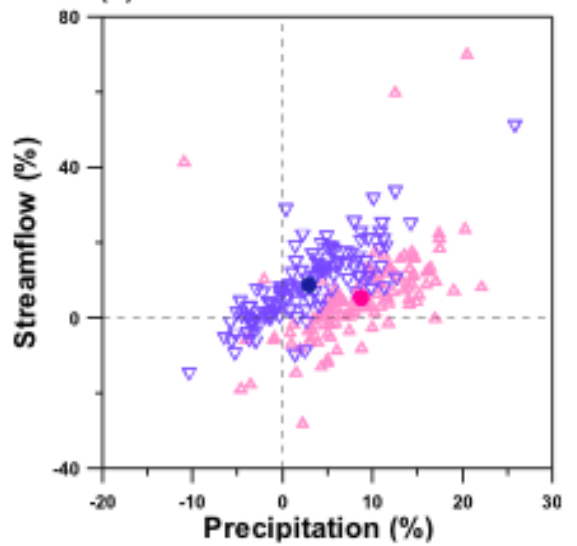

(c) SON

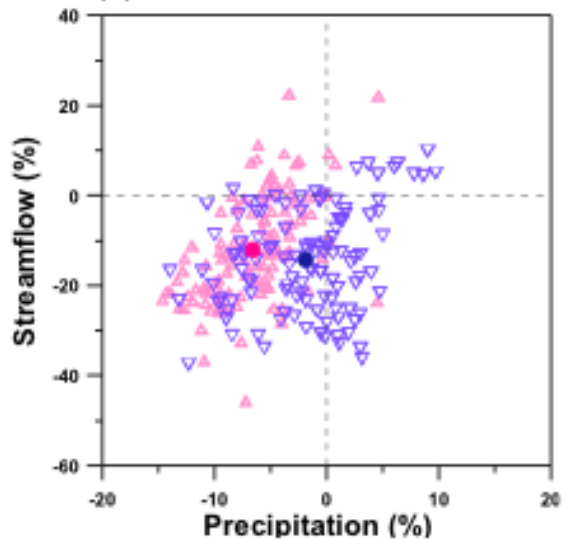

(b) JJA

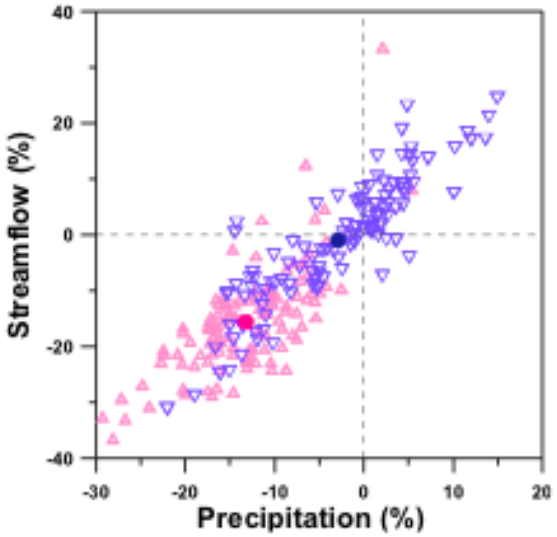

(d) DJF

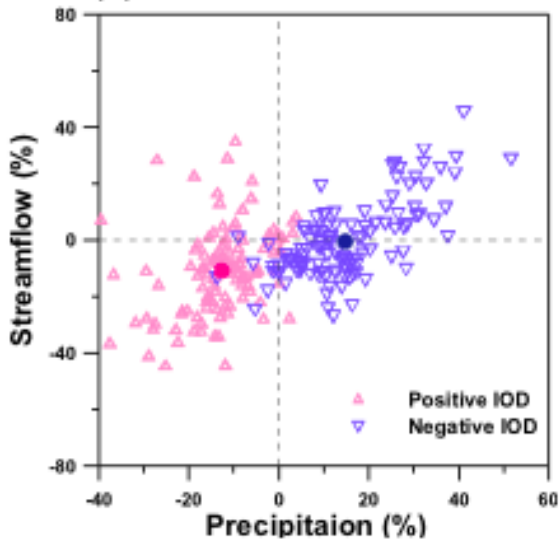

Figure 10. Scatter plot of percent anomaly (de partures from the 1971-2000 normal) changes between precipitation and streamflow in different IOD types (Positive and Nega tive) over the KP. (a), (b), (c), and (d) indicate pattern of hydrometeorological variability in each sub-watershed during diffe rent season in the $\mathrm{KP}$, respectively.

\section{Conclusions}

In this study, we used statistical models to analyze nonlinear behavior links of the atmospheric teleconnections between hydrological variable and climate indices. The Indian Ocean Dipole (IOD) mode, which is a major ocean-related climatic factor in the Indian Ocean, w as applied to analyze the hydro-meteorological impacts in the East Asian region and Korean Peninsula. Atmospheric teleconnections were analyzed by Principal Component Analysis (PCA) using the Singular Spectrum Analysis (SSA) technique; nonlinear lag-correlation between climate indices and hydrological parameters was calculated by the mutual information (MI) technique. The primary results are summarized as follows.

(1) The disadvantage of linear correlation analysis using correlation coefficient is that nonlinear relations cannot be determined. To compensate for this, we used the mutual information (MI) technique, which takes nonlinear correlation into consideration. The MI result can also be used to quantitatively evaluate the correlation betw een the climate indices and the hydrological variables and their lag-time correlation. The values obtained through the MI technique can be used to analyze nonlinear behavior characteristics using the Kernel joint probability density function.

(2) Results from the composite analysis of precipitation during p-IOD and n-IODevents in the KP in warm season (June-September) showed that the sub-watershed in the KP during p-IOD years decreased substantially from that during normal years. The annual/JJAS precipitation during $\mathrm{p}$-IOD event show ed a substantially decreasing tendency compared to those during long-term normal years. The n-IOD events showed an almost neutral condition for summer precipitation. 
(3) Teleconnection-based nonlinear and linear CCs w ere performed betw een climate indices and hydrological variables using LR and KDE based on MI results. Results from nonlinear CCs were higher than those from linear correlations, and IOD had a direct influence on precipitation anomaly time series over the KP. This study demonstrated a methodology for teleconnection-based long-range water resources management to reduce climate uncertainty when abnormalSSTA occurs in the TIO region.

(4) Furthermore, the relationship identified between climate indices and hydrometeorological variables by advanced statistical methods such as MI techniques can help understand the possible changes resulting from natural or anthropogenic environmental drivers. In addition, it can be useful for long-term water resources prediction and they can help establishing $w$ ater-related policies and their management.

Although the results of this study are based on limited observational data, the relationship between climatic factors and hydrological parameters, in areas with high seasonal variability and a high degree of uncertainty regarding hydro-meteorological data is critical to developing a plan for sustainable freshw ater management in the future. The results of this diagnostic study can be utilized in decision-making processes to minimize climate-related disasters, such as floods and droughts through seasonal prediction and by developing optimal strategies to ensure the best management practices for water use under a changing climate.

Author Contributions: Conceptualization, Resources, Formal analysis, W riting - original draft, J.K., S.Y., and S.O.; Data curation, Methodology; J.K. and S.Y., Writing - review \& editing; J.K. and S.Y.

Funding: This work was supported by the Seoul Institute of Technology, Seoul, South Korea. And also we appreciate that the support of the State Key Laboratory of Water Resources and Hydropower Engineering Science, Wuhan University, China. The second and third authors a cknowledge that the support of climate data by the APEC Climate Center (http://www.apcc21.org/).

Conflicts of Interest: The authors declare no conflict of interest.

\section{References}

1. Wang B.; Wu, R.; Fu, X. Pacific-East Asia Teleconnection: How Does ENSO Affect East Asian Climate? J. Climate. 2000, 13, 1517-1536.

2. Pizarro, G.; Lall, U. El Niño-induced flooding in the U.S. West: What can we expect? Eos Trans. Amer. Geophys. Union. 2002, 83, 349-352.

3. IPCC (Intergovernmental Panel on Climate Change). Managing the Risks of Extreme Events and Disasters to Advance Clima te Change Adaptation (SREX) -Special Report of the Intergovernmental Panel on Climate Change. Cambridge University Press, 2007, 1-594

4. Horel, J.D.; Wallace, J.M. Planetary-scale a tmospheric phenomena a ssociated with the Southern Oscilla tion. Mon. Weather Rev. 1981, 109, 813-829.

5. Kim, J.S.; Jain, S.; Yoon, S.K. Warm season streamflow variability in the Korean Han River Basin: Links with atmospheric te leconnections. Int. J. Climatol. 2012, 32, 635-640. doi:10.1002/joc.2290.

6. Yoon, S.K.; Kim, J.S.; Lee, J.H.; Moon, Y.I. Hydrometeorological variability in the Kore an Han River Basin and its sub-watersheds during diffe rent El Niño phases. Stoch. Environ. Res. Risk Assess. 2013, 27, 1465-1477.

7. Lee, T.S.; Ouarda, T.; Yoon, S.K. KNN-based Local Linear Regression for the Analysis and Simulation of Low Flow Extremes under Climatic Influence, Climate Dynamics, 2017, 49, 3493-3511.

8. Piechota, T.C.; Dracup, J.A. Drought and regional hydrologic va riation in the United States: Associations with the El Niño-Southern Oscillation. WaterRes. Res. 1996, 32, 1359-1373.

9. Piechota, T.C.; Chiew, H.S.; Francis Dracup, J.A.; McMachon, T.A. Sea sonal streamflow forecasting in eastern Australia and the El Niño-Southern Oscillation. Water Res. Res. 1998, 34, 3035-3044.

10. Saji, N.H.; Goswami, B.N.; Vinayachandran, P.N.; Yamagata, T. A dipole mode in the tropical Indian Ocean, Nature. 1999, 401, 360-363.

11. Yoon, S.K.; Lee, T. Investigation of hydrological variability in the Korean Peninsula with the ENSO teleconnections, Proc. Int. Associ Hydrol. Sci. 2016, 374, 165-173.

12. Ashok, K.; Guan, Z.; Yamagata, T. Influence of the Indian Ocean dipole on the Australian winter rainfall. Geophys. Res. Lett. 2003, 30, 1821. doi,10.1029/2003GL017926. 
13. McPhaden, M.J.;Zebiak, S.E.; Glantz, M.H. ENSO as an integrating concept in Earth Science. Science. 2006, 314, 1740-1745.

14. Pradhan, P.K.; Preethi, B.; Ashok, K.; Krishna, R.; and Sahai, A.K. Modoki, Indian Ocean Dipole, and we stern North Pacific typhoons, Possible implica tions for extreme events. J. Geophys. Res. 2011, 116, D18108, doi,10.1029/2011JD015666.

15. Klein, S.A.; Soden, B.J.; Lau, N.C. Remote sea surface temperature variations during ENSO, Evidence for a tropical a tmospheric bridge. J. Climate. 1999, 12, 917-932.

16. Lau, N.C.; Nath, M.J. Atmosphere-ocean variations in the Indo-Pacific sector during ENSO episodes. J. Climate. 2003, 16, 3-20.

17. Behera, SK.; Krishnan, R.; Yamagata, T. Unusual ocean-atmos phere conditions in the tropical Indian Ocean during 1994. Geophys. Res. Lett. 1999, 26, 3001-3004.

18. Webster, P.J.; Moore, A.M.; Loschnigg, J.P.; Leben, R.R. Coupled ocean-atmosphere dyna mics in the Indian Ocean during 1997-98. Nature. 1999, 401, 356-360.

19. Saji, N.H.; Yamagata, T. Structure of SST and Surface Wind Variability during Indian Ocean Dipole Mode Events, COADS Observations. Bull. Am. Meteor. Soc. 2003, 16, 2735-2751.

20. Leavesley, G.H.; Lichty, R.W.; Troutman, B.M.; Saindon, L.G. Precipitation-Runoff Modeling System, User's Manual. Water Res. Invest. 1983, 83-4238, U.S. GeologicalSurvey, Denver, Colorado.

21. Dressler, K.A.; Leavesley, G.H.; Bales, R.C.; Fassnacht, S.R. Evaluation of gridded snow water equivalent and satellite snow cover products for mountain basins in a hydrologic model. Hydrol. Processes. 2006, 20, 673-688.

22. Moon, Y.I.; Lall, U. Atmospheric flow indices and interannual Great Salt Lake variability. J. Hydrol. Eng. 1996, 55-61.

23. Moon, Y.I.; Rajagopalan, B.; Lall, U. Estimation of mutual information using kernel density estimators. Phys. Rev. E. 1995, 52, 2318-2321.

24. Martinerie, J.M.; Albano, A.M.; Mees, A.I.; Rapp, P.E. Mutual Information, Strange Attractors, and the Optimal Estimation of Dimension. Phys. Rev. 1992. A 45, 7058-7064.

25. Gao, J.; Zheng, Z. Direct dynamical test for deterministic chaos and optimal embedding of a chaotic time series. Phys. Rev. 1994, E 49, 3807.

26. Joe, H. 1989. Relative entropy measures of multiva riate de pendence. J. Am. Stat. Assoc. 84, 157-164.

27. Granger, C.; Lin, J. Using the mutual information coefficients to identify lags in nonlinear models. J. Time Series Anal. 1994, 15, 371-384. 